This is an Accepted Manuscript of an article published by ROUTLEDGE / TAYLOR \& FRANCIS in JOURNAL OF MARKETING MANAGEMENT On 13 December 2014, available online:

http://www.tandfonline.com/10.1080/0267257X.2014.989890 


\title{
The rise of inconspicuous consumption
}

\author{
Giana M. Eckhardt* \\ Russell W. Belk \\ Jonathan A.J. Wilson
}

Giana M. Eckhardt is Professor in Marketing, School of Management, Royal Holloway University of London, Egham, Surrey, UK, giana.eckhardt@rhul.ac.uk. Russell W. Belk is Distinguished Research Professor and Kraft Foods Canada Chair in Marketing, Schulich School of Business, York University, Toronto, Ontario, Canada, rbelk@schulich.yorku.ca. Jonathan A.J. Wilson is Senior Lecturer in Marketing, School of Business, University of Greenwich, London, UK, j.a.jwilson@greenwich.ac.uk.

*contact author

Giana M. Eckhardt is Professor of Marketing, Royal Holloway University of London. Giana has published widely in the field of consumer culture theory; in particular on issues related to consumer behavior in Asia, branding, and globalization. She has published over twenty articles in journals such as Harvard Business Review and Journal of Consumer Research. She is coauthor of The Myth of the Ethical Consumer (Cambridge University Press). She is a past co-chair of the Consumer Culture Theory conference and is on the editorial review board of Consumption, Markets and Culture. Her research has won awards from the Sheth Foundation and the Marketing Science Institute, and been featured in outlets such as The Economist, The Atlantic, Wall Street Journal, and on National Public Radio. Giana has received research grants from the Marketing Science Institute, and has presented her work at top institutions and conferences around the world, including at the United Nations CSR Global Forum. 
Russell W. Belk is past president of the International Association of Marketing and Development and is a fellow and past president of the Association for Consumer Research. He initiated the Consumer Behavior Odyssey, the Association for Consumer Research Film Festival, and the Consumer Culture Theory Conference. His awards include the Paul D. Converse Award, the Society of Marketing Advances Distinguished Marketing Scholar Award, and the Sheth Foundation/Journal of Consumer Research Award for Long Term Contribution to Consumer Research. His research involves the meanings of possessions, collecting, gift-giving, materialism, sharing, and global consumer culture. He is currently Distinguished Research Professor and Kraft Foods Canada Chair in Marketing at the Schulich School of Business, York University in Toronto, Canada and holds honorary professorships in North America, Europe, Asia, and Australia. His work is often cultural, qualitative, and visual. He has published approximately 550 articles, books, chapters, and videos.

Jonathan A.J. Wilson is an academic, consultant, speaker, journalist and musician with industry experience spanning 20 years. His work has taken him throughout Europe, the Muslim world, and Asia tackling the following areas: Cultural phenomena, Advertising, Branding, Public Relations, Consumer Behaviour, Ethnocentric and hybrid identity-sharing, Sport, Music, Halal, Islamic finance and economics, and Muslim world issues. Jon has received media coverage from Amilin TV, Astro Awani, BBC, Evening Standard, The Guardian, NME, Republika, Sky News Arabia, Thomson Reuters, and The Times. Jon is Editor-in-Chief of the Journal of Islamic Marketing, and is an Associate Member of the UK All Party Parliamentary Group (APPG) on Islamic Finance and Diversity in Financial Markets. Over the last 5 years, Jon has spoken at conferences on over 85 occasions to academics and practitioners internationally; and has published over 145 pieces of work, winning several awards. 


\begin{abstract}
Ever since Veblen and Simmel, luxury has been synonymous with conspicuous consumption. In this conceptual paper we demonstrate the rise of inconspicuous consumption via a wide ranging synthesis of the literature. We attribute this rise to the signaling ability of traditional luxury goods being diluted, a preference for not standing out as ostentatious during times of economic hardship, and an increased desire for sophistication and subtlety in design in order to further distinguish oneself for a narrow group of peers. We decouple the constructs of luxury and conspicuousness, which allows us to reconceptualise the signalling quality of brands and the construct of luxury. This also has implications for understanding consumer behaviour practices such as counterfeiting and suggests that consumption trends in emerging markets may take a different path from the past.
\end{abstract}

\title{
Summary statement of contribution
}

While the marketing literature equates luxury with conspicuousness, we demonstrate in this conceptual paper, via an extensive literature review, that conspicuousness is not the same as luxury and that inconspicuous luxury consumption is on the rise. This leads to us redefine the luxury construct and re-evaluate the signalling quality of brands. This reconceptualization has implications for understanding how consumers emulate others through practices such as counterfeiting, and what shape consumption trends in emerging markets may well take.

\section{Keywords}

Branding, luxury, inconspicuous consumption, conspicuous consumption 
In the 1985 movie Back to the Future, Marty McFly travels back in time 30 years to his parents' high school years and becomes known as Calvin Klein, because seeing the CK name on his underwear, people assumed it must be his own. During the years between these scenes, brand logos went from invisible to highly visible devices for marketing brands and the consumers who wear them. Recently the logo for Ralph Lauren's Polo in the nouveau riche countries of Asia has grown from a small polo pony to an in-your-face "big pony" icon taking up much of the shirt front. Similarly, Mercedes and Volvo have both made the brand emblems on their cars bigger in models targeted to these same Asian markets. These examples illustrate the traditional importance of conspicuousness to branding, a relationship that has been observed and analysed from Veblen (1899/1973) onwards.

What is conspicuous consumption? We follow Veblen (1899/1973) in defining conspicuous consumption as the purchase of expensive goods to wastefully display wealth rather than to attempt to satisfy more utilitarian needs of the consumer, for the sole objective of gaining or maintaining higher social status. In this view, the raison d'être of a luxury brand is its visibility and ability to signal and convey meaning, at the apex of a collection of associations and elements, which in turn generate economic and social capital (Holt 2004). However, in contrast to this tradition, we suggest the relationship between brands and conspicuousness is weakening, and provide an analysis as to why this is so. We agree with Berger and Ward (2010) in defining inconspicuous consumption as the use of subtly marked products which are misrecognised by most observers, but facilitate interaction with those who have the requisite cultural capital to decode the subtle signals.

While branding has been examined from a variety of perspectives (e.g., Arvidsson 2006; Brown 2001; Fournier 1998; Holt 2004; Lury 2004; Schroeder and Salzer-Mörling 2006; 
Twitchell 2004), inconspicuous brands have been conspicuously absent in these treatments. The phenomenon of inconspicuous consumption has been noted (e.g., Berger and Ward 2010; Postrel 2008), but the reasons for such a shift are little understood or studied. They are important to study because the rise of inconspicuous consumption demonstrates that luxury consumption does not need to equate to conspicuous consumption, a relationship that has been assumed up until now in the marketing literature (e.g., Mason 1998; Sirgy, Johar, and Wood 1986; Sundie, Kenrick, Griskevikius, et al. 2011). Moreover, in the past, consumers could signal status to society at large and their social group peers simultaneously, whereas now, with the rise of inconspicuousness, few, other than certain social group peers, will be able to decipher these signals. We seek the precipitants of such shifts through a review of wide ranging literature that enables a deeper understanding of this emerging phenomenon. By decoupling luxury from conspicuousness, which prior work on luxury and conspicuousness has not done, our contribution is to explain and theorize this shift from conspiciousness to inconspicuousness. We see this as part of an inward hedonistic turn with the concern for impressing others narrowed to other elites. Like the gourmet food enthusiast, the coffee connoisseur, or the vinophile, the pleasure is not so much in flaunting wealth and taste as enjoying it in the company of other elite enthusiasts. First, we outline the three phases of the shift from conspicuousness to inconspicuousness, then we provide three explanations for why this shift has occurred, and finally we outline the implications of this shift, for both marketing theory and managerial practice, and recommend future research paths.

\section{Phase 1: Traditional Conspicuous Consumption}

Since Veblen (1899/1973) coined the term conspicuous consumption, the received wisdom has been that wealthier consumers seek to distinguish themselves by flaunting their 
affluence via conspicuous luxury consumption unaffordable to the masses (Han, Nunes and Dreze 2010) and by conspicuously wasting their time and money in a way the masses cannot. For generations of sociologists, anthropologists, psychologists, and marketers, the basic engine of consumption has been seen to be the race for class and status (e.g., Brooks 1981; Dittmar 1992, 2008; Douglas and Isherwood 1979; Doyle 1999; Fussell 1983; Mason 1981; McCracken 1988; Packard 1959, Simmel 1904/2011; Tawney 1920), although some consumers are found to be more susceptible to such concerns than others (Eastman, Iyer, and Thomas 2013). The search for status has been seen to relate to the individual trait of materialism (Eastman, Fredenberger, Campbell, and Calvert, 1997) - the envy component of which leads to an insatiable desire for consumer goods a little better than our friends' and neighbours' (Belk 1988).

Status competition has even been detected between corporations (Podolny 2005). In the traditional view, because innovations in consumption and fashion and the knowledge to successfully deploy them bring distinction when they are first adopted by high status consumers (Bourdieu 1984), they become status markers (Douglas and Isherwood 1979), at least until they "trickle down" to the masses (Simmel 1904/2011) prompting further innovations at the top of the status latter. Social comparison means that we are forever comparing ourselves to those a status level above us (Festinger 1954). We envy those "above" us and covet their possessions. When the envy is malicious, the desire is to "level down" by depriving those above of their advantages (Schimmel 2008). But when, more commonly, envy is benign, this leads to a desire to "level up" by emulating envied others' consumption (Belk 2008, 2011). The resulting race for status has been seen to result in a treadmill of "keeping up with the Joneses" (Matt 2003; Stearns 1999). With mass marketing of mass produced consumer goods the treadmill started running faster, but 
the result was a "democratization of desire" without a corresponding democratization of access to ever receding class privileges (Leach 1993).

\section{Phase 2: The Rise of Luxury for the Masses and the Death of Class}

Recently terms such as 'luxury' in a postmodern, multicultural, transnational, and urban world have been reframed, giving birth to the concept of "new luxury" (Taylor, Harrison, and Kraus 2009). It has also been called democratized luxury or luxury for the masses (Danziger 2005; Silverstein and Fiske 2003a; Thomas 2007). New luxury involves affordability, massmarket proliferation, the divorce of status and class, and availability in the mass market, ideally without undermining a brand's luxury status. While contemporary new luxury is seen in down market models of luxury automobiles and relatively low priced accessories by high end luxury goods makers (e.g., Dior sunglasses, Louis Vuitton wallets, and Hermes scarves), earlier versions of "populuxe" showed up in 1950s and 1960s in the form of American car tail fins, Naugahyde furniture, and the themed resorts of Las Vegas (Hine 1987; McCracken 2005). Marchand (1985) sees even earlier signs in the rise of matched ensembles of bedroom and living room furniture in the 1920 s.

But the very watering down of what luxury brands once meant has led to what Thomas (2007) characterizes as luxury losing its lustre. Together with the rise of counterfeits (e.g. Lin 2011), and the production of less expensive new luxury goods (Silverstein and Fiske 2003b), the meaning of luxury has been diluted. Concomitant to these changes there has been a shattering of old class models leading to what Pakulski and Waters (1996) call "the death of class." They attribute this alleged declassification of society to two simultaneous causes. One is the cultural homogenization brought about by public education, progressive income taxes, and welfare benefits. This results in fewer consumption-based boundaries. The other cause Pakulski and 
Waters (1996) detect is fragmentation of status in society into myriad lifestyle groups that largely replace class considerations. They do not contend that privilege and rank have disappeared, but rather that these hierarchies have become much more complex than envisioned by simplistic capitalist class formations based on ownership of capital, land, and human resources (Polyani 2001).

\section{Phase 3: The Rise of Inconspicuous Consumption}

In the past eras of democratized faux luxury and knockoffs for the middle classes merely led to further innovation by higher social classes. Today the divorce of social class and luxury in an anonymous society (Hemetsberger, von Wallpach and Bauer 2012) as well as the market for accessing luxuries from expensive automobiles to designer couture and handbags by short term rental rather than purchase (Bardhi and Eckhardt 2012) make all but the most expensive luxury goods lose their exclusivity. If one can pay a small membership fee to be able to access a BMW via a car sharing service for a couple of hours, the BMW brand is no longer a symbol of the status or the economic capital of the driver (Bardhi and Eckhardt 2012; Belk forthcoming). As Hemetsberger et al. (2012) observe, luxury consumption is no longer a marker of social class, and luxury is now more about meaningful objects and activities that consumers might experience as luxury rather than conspicuous brand names (Hudders and Pandelaire 2013; Williams and Atwal 2013). In an anonymous society of strangers, casual acquaintances, parking valets, restaurant maitre 'ds, and hotel clerks defer to flash, unable to tell the difference between what is owned versus what is accessed for a short period of time or what is owned at the sacrifice of other areas of consumption such as books, healthcare, and education (Mukherjee 2006). In an era of smart phones and the Internet, even the cultural capital that consumers once had to acquire 
through a privileged upbringing and a fine education (Bourdieu 1984; Holt 1998) is now able to be acquired with a few finger flicks, at least in some consumption categories.

Stemming from some of the same forces, we see another development: the rise of inconspicuous brands -- brand signals that are not readily apparent or visible to most consumers (Berger and Ward 2010). Inconspicuous brands have low visual prominence, and use quiet or discreet signals in their design (Han, Nunes and Dreze 2010). Han et al. (2010) find that "Wealthy consumers low in need for status want to associate with their own kind and pay a premium for quiet goods only they can recognize" (p. 15). For example, Anaya (2013) recently pointed out that many traditional luxury brands are making their logos much more subtle, or not visible at all, and asks what does it mean when Louis Vuitton, the world's largest luxury brand, is getting rid of its ubiquitous 'LV' logo on its handbags and shifts its focus away from the very trademarks on which its success has been built? To try and understand this shift toward inconspicuous consumption, we explore three explanations for why this is happening.

\section{The Signalling Ability of Traditional Luxury Goods is Diluted}

As a starting point, we can look toward understanding the changing relationship between conspicuousness and status as it affects the signalling ability of traditional luxury goods. Truong, Simmons, McColl, and Kitchen (2008) found that status and conspicuousness are two different constructs. Specifically, they found that the Audi brand was higher in status but lower in conspicuousness compared to the BMW brand. And while Levi's was found to be a low status brand, it had the same level of conspicuousness as higher status Polo Ralph Lauren (Truong et. al. 2008). This is because status connotes high quality, luxury and perhaps class, while conspicuousness is more closely tied to recognisability, image and appearance. Thus brands can vary on both these dimensions independently. Given this decoupling, there should not 
necessarily be a direct correlation between status and conspicuousness. Indeed, the conspicuousness of brands is positively associated with price only to a point and then declines with higher price objects in the same product category - an inverted U relationship - suggesting to Berger and Ward (2010) that those who can afford truly high status brands prefer less conspicuous consumption. Alternatively it may be that luxury goods makers have created this reversal based on the image of the vulgar nouveau riche who held sway in Veblen's day (Costa and Belk 1990). Han, Nunes and Dreze (2010) suggest that patricians - those at the top of the socio economic pyramid who have less need to signal status to others - will pay more for inconspicuously branded products; that is, not only do they prefer less conspicuous consumption, but they will pay a premium for inconspicuousness or simply avoid gauche luxury consumption.

Brand offerings have begun to respond to this preference; for example, Louis Vuitton uses a subtle $\mathrm{V}$ in the knitted pattern of its sweaters rather than its formerly ubiquitous and easily identifiable 'LV' logo (Dougan 2012). In part this may be because the rich prefer not to provoke envy and anger in times of economic austerity (Belk 2011; Ledbury Research 2012). In part it may be due to the desire of consumers with high cultural capital to distinguish themselves from the over-the-top conspicuous consumption of the nouveaux riches and the aspirational consumption of lower status consumers who weaken a brand image by consuming more mass market versions of luxury goods, as with rappers' consumption of "bling" jewellery, and "chavs" consumption of Burberry goods in the UK (The Economist 2005; Nueno and Quelch 1998; Silverstein and Fiske 2003a; Thomas 2007; Wilson and Morgan 2011). And in part it may be that in an anonymous urban society with increasing options to temporarily rent or lease luxury purses, cars, and dresses, it is getting increasingly difficult to "know if the guy who drives past me in a Ferrari owns it or is just renting it for the weekend" (The Economist 2005). 
At the other end of the economic continuum we might expect that there is little conspicuous consumption due to lack of income. But with urban anonymity it is also possible to sacrifice less visible "necessities" like food, medical care, and adequate shelter in order to afford more visible "luxuries" like designer clothing, watches, and mobile phones - a phenomenon which Belk (1999) terms "leaping luxuries." For instance, Pinheiro-Machado (2010) finds that in Brazil a maid is more likely than her employer to own a genuine luxury handbag. And for those who cannot afford to make such sacrifices, there are knock-offs and counterfeits. These trends dilute the status signalling ability of luxury goods (Lin 2011). In addition, there is evidence that those with well-established social status seek luxury goods not so much for their status signalling ability as for the pleasure they provide (Postrel 2008). In investigating what luxury means from a consumer point of view, Bauer, von Wallpach and Hemetsberger (2011) found that for consumers, luxury is context- and self-related. That is, something may be a luxury because it was purchased for rare moments of pleasure (e.g, a weekend at a luxury hotel or spa). Many consumers also value inconspicuous but pleasurable 'little luxuries' in their everyday lives, like the so-called "lipstick effect" in times of hardship (Hill, Rodeheffer, Griskevicius, et al. 2012, Wilson 2014). Such consumers are more interested in enhancing their personal self than reflecting a luxurious lifestyle through conspicuous consumption. Thus, luxury is becoming disconnected to social class and conspicuousness for multiple reasons (Bauer et. al. 2011; Stylus 2014; Sullivan and Gershuny 2004; Wilson 2014).

\section{Inconspicuousness is the New Conspicuousness}

How can we understand the nature of brands' ability to signal status given this shift from conspicuous to inconspicuous? One clue can be found in a study by Charles, Hurst, and Roussanov (2007). Using nationally representative U.S. data they found that blacks and 
Hispanics devote a larger portion of their incomes to conspicuous clothing, jewellery, and automobiles than comparable income whites. They convincingly show that these differences are not due to preference differences, or to their histories of being recipients of discrimination that has generated a resulting need to demonstrate to store clerks and others that they can afford to spend (Mukherjee 2007). Instead their spending on conspicuous consumption appears to be related to racial stereotyping within their community. Because blacks and Hispanics in the U.S. overall have lower incomes than whites, there is a greater need for members of these groups to distinguish themselves and elevate their status in order not to be judged by the racial stereotype of poverty. In order to do so, they spent less on lower visibility goods like education, health care, and savings. Whites, by contrast, come from a relatively privileged racial group and are therefore more inclined to spend inconspicuously, devoting more to health, education, and retirement savings and less to visible luxuries. Moreover, in states where there was less of an income gap between these minority groups and whites, the differences in conspicuous consumption were attenuated, presumably because the poverty stereotypes were not as strong.

One explanation for these findings is that blacks and Hispanics, in states where the income gap is high, are engaging in compensatory consumption (Rucker and Galinsky 2013; Wicklund and Gollwitzer 1982). Rucker and Galinsky (2008) demonstrate that when consumers are lacking power, they show an increased willingness to pay for products but only when they are status-related. That is, consumers will try and alleviate or compensate for their state of powerlessness by acquiring luxury products that overtly (conspicuously) signal status to others. Indeed, Levitt and Dubner (2006) note that blacks, who tend to have lower economic power, are more likely to name their children after brand names that convey status, such as Harvard or Lexus. 
There is also evidence that lower status groups in India spend relatively more on their weddings (Bloch, Rao, and Desai 2004) and that when wealthy Hong Kong residents move to Canada they engage in less conspicuous consumption than they did in their homeland (Chung and Fischer 2001). Such findings suggest that differential conspicuous consumption outside of the U.S. may be guided by different reference groups on the world stage. That is, entire nations may be stereotyped as being impoverished relative to more economically privileged nations. Postrel (2008) puts forth a similar explanation for the conspicuous consumption of nouveau riche consumers in otherwise poor countries such as the BRIC nations of Brazil, Russia, India, and China, which suggests that there should be a shift from conspicuous to inconspicuous consumption as these nations become wealthier and shed their "Second or Third World" images.

In China we can see this happening already. For example, wealthy Chinese have been known for preferring prominent logos (Pinheiro-Machado 2010). But now they are increasingly shunning overt displays of wealth, to the extent of removing labels from clothing in order to avoid appearing too ostentatious (CPP Luxury 2013). Stylus (2014) attributes this desire to not flaunt wealth to today's global climate of austerity. Thus, the subtle signals that will only be picked up by other elites become more important than signals that will be understood by everyone, as with Veblen's (1899/1973) prediction that nouveau riche fin de siècle Americans sought to signal status so boldly that "he who runs may read" these signs. In fact these bold conspicuous luxuries become badges of pretention, as when wealthy Hong Kong consumers put down the splashy consumption of increasingly prevalent wealthy mainland Chinese coming to Hong Kong to shop (Pinheiro-Machado 2010). This preference for subtle signals by the very elite mirrors Berger and Ward's (2010) findings that conspicuousness is desired in the mid-price 
levels, but not at the very high price levels. Subtle signals can also be a deliberate strategy to restrict imitation by lower social groups by making tastes harder to follow (Hebdige 1979).

Inconspicuous brands are by definition subtle and are often "refined" in terms of the way they are designed and their aesthetics. Conspicuous brands utilize "loud" brand signals, and achieve this via large, bright logos or other overt brand aesthetics. In China, the largest brand market in the world, we can examine China's first two home-grown luxury brands: Shanghai Tang (http://www.shanghaitang.com/) and Shang Xia (http://www.shang-xia.com/en). Shanghai Tang, a lifestyle brand now owned by the Richemont luxury group along with Cartier and Montblanc, is an unrefined brand; it is loud in terms of its colors and stereotyped and old fashioned in terms of its aesthetics, and reads as periodicised with the referent period being Old Shanghai in the treaty port days before communism. Its Orientalized brand image is aimed at tourists more than locals, and $\mathrm{Wu}$, Borgerson and Schroeder (2013) suggest that its appeal to non-Chinese is due to the brand's ability to provide a set of codes that convey a cosmopolitan Chinese identity, if borrowed from an earlier pre-communist era.

In contrast, the Shang Xia brand, started by Hermes, is understated and extremely expensive - one can purchase Ming dynasty style chairs for 1 million RMB each - and is targeted toward local Chinese. Only others in the very top of the elite class would recognise these brand signals. Bergstrom (2012) highlights that Shang Xia seeks to elevate traditional Chinese handicrafts, and indeed redefine what a modern Chinese luxury brand can be by focusing on storytelling to help consumers build contemporary meanings for Chinese traditions. As Bergstrom (2012) notes, "It lacks the flash and conspicuous status that most brands jangle in front of Chinese consumers to get their attention... [and] this modesty speaks to upwardly mobile Chinese looking to demonstrate their connoisseurship in a more refined manner" (p. 177). In this 
sense such subtle high end brands bring cultural capital back into the equation, but regarding the brands themselves. This is a bit like wine expertise perhaps, but in that case the "brand" may be less important than the terroir (Allhoff 2008; Smith 2007). The wine consumer may be able to call up Robert Parker's ratings on her mobile phone, but this is of little help in a blind tasting. Refinement, subtlety, and sophistication are characteristics that Levy (1986) found associated with higher status beverages. Making discriminations between different wines has long been seen as a mark of taste. Taste cultures do not disappear with inconspicuous consumption; they instead become more complex and difficult to acquire (Bayley 1991; Gronow 1997; Warde 1997).

Given the current trends in China, subtle inconspicuous branding should become popular in the region as the market matures, suggesting that Shanghai Tang is not subtle enough as a luxury brand if it wants to succeed among elite consumers in China. Shang Xia is emotionally resonant, has a great brand origin myth, and is bringing back pride in Chinese craftsmanship, whereas Shanghai Tang is not in touch with the local marketplace, as it is targeting tourists who need readily understood, conspicuous Chinese signals from the brand so they can be decoded by their social groups at home. Wu et. al. (2013) point out that local Chinese do wear Shanghai Tang branded clothing, but they do so conspicuously, to stand out, mostly to foreigners/Westerners. Brands like Shang Xia, by contrast, resonate with the current Chinese marketplace for understated luxury. Similarly, BMW will produce cars in China under the Zhinuo brand name and Mercedes will offer new models with the Denza brand (The Economist 2013); like Hermes, they are creating local brands which will radiate luxury in a more subtle way. Croll (2006), Tian and Dong (2011), and Zhou and Belk (2004) all find that Chinese conspicuous consumption after Deng's opening of the economy in the late 1970s was due to the 
sudden influx of Western goods and the liberation from bland unisex clothing, but that now the former fascination with Western luxury goods has become more ambiguous and muted as pride in Chinese brands increases.

To further illustrate the complexity of these constructs in Asia, according to a survey reported by Chadha and Husband (2006) of Tokyo women in their 20s, 94 percent reported owning at least one Louis Vuitton item, 92 percent reportedly owned Gucci, with Prada (57 percent), and Chanel (51 percent) also quite high. When this many people own such luxury goods, it is a matter of fitting in rather than standing out (Belk and Pollay 1985; Griffiths 2013; Weisz, Rothbaum, and Blackburn 1984). It would be conspicuous not to own such goods under these circumstances, and thus we can think of not owning these ubiquitous brands as a kind of mutated conspicuousness: standing out by not owning a brand.

Many government officials in China have to have inconspicuous logos on their luxury goods because no one must know that they have such expensive consumer goods. Government salaries are low; the source of large disposable incomes for many of these high ranking officials is corruption. While everyone knows the corruption happens at the top levels, it cannot become too public (c.f. the Bo Xilao trial and the New York Times exposé of the wealth of the family of Wen Jiabao). Thus, inconspicuousness may be valued by this group of elites, which is a major part (perhaps even the majority) of the elite class in China (Lu 2008), although this is debated (Wang 2010). The desire for inconspicuous luxury brands in China is manifested in the demand for very subtle or no logos on luxury briefcases, watches, and clothing, as well as an increased demand for experiential luxury rather than material luxury. That is, the elite class may prefer to enjoy a spa weekend, a fancy dinner, or travel to play golf in Hainan rather than just buying the latest handbag or sports car model. While experiences can certainly be conspicuous, it is less 
lastingly visible compared to carrying around a logoed LV handbag. We can interpret this shift to experiential luxury as a shift toward inconspicuousness.

We have examined Asia, and in particular China, as this is the region most well-known for its conspicuousness (Wong and Ahuvia 1998). We can see that the transition to inconspicuousness is complex and being interpreted by both consumers as well as marketers in varying ways. Signals that were formerly used to signal conspicuousness (e.g. LV handbags) are now being used to fit in, subtle signals are now preferred, but among the cognoscenti they can be even more inconspicuous, and there is a shift from luxury products to experiences as they are less recognizable by the general public. This rapidly changing hotbed of consumer culture in Asia provides an insightful context demonstrating that the nature of luxury is not inherently tied to conspicuousness.

\section{Creating Inconspicuousness Luxury}

How can brands respond to this shift? A subtle, elegantly designed inconspicuous brand, which signals luxury in a qualitatively different way than a conspicuous brand, relies upon complexity. Sophistication in design implies meticulous engineering and an intricacy that elevates the status of the designer and, by extension, the consumer. When considering how the concept of sophistication has been applied to fashion and fashion systems, it is clear that alongside a desired and projected elite status, there should also be an appearance of effortlessness and a sense of exclusivity unattainable by the masses. Arguably, luxury may attach to any commodity with these characteristics, although success in being accepted as emblematic of good taste also depends upon adoption by those regarded as possessing high cultural capital. Such elevated taste invokes what Leibenstein (1950) terms snob appeal rather than the mere monetary power of "Veblen effects" or the imitative implications of "bandwagon effects." 
Subtlety and snobbery move thinking beyond concepts of social class, decoupling the idea that brand strength and attractiveness are delivered through share of voice or "loudness." Instead, nuanced minimalism and co-opting the mainstream are the tacit cues that transport brands into different contexts and spaces, allowing for greater private pleasure as well as brand transcendence and an ability to create new forms of cultural capital. Not only are the branded goods sumptuous and subtle, so are the retail atmospheres in which they are sold. Outka (2009) describes how London's Selfridges department store did this. Price tags were subtle or missing entirely, it was implied that the merchandise was handcrafted by world artisans, and customers were treated more like guests with personal attendants, a library, and writing tables equipped with paper and ink. In China too, service in high end shops and departments is deferential and respectful and clerks must also have refined manners (Hanser 2008).

Interest and developments in China's youth population consisting of 500 million people under the age of 30 have been studied by Bergstrom (2012). She presents a landscape of interdependent individuals who converge around brands; set boundaries through branded consumption, social media, and the use of symbols and luxuries; and reverse currents through leveraging the practice of 'see and be seen.' Sophistication and subtlety are paramount and add texture to consumption, without which 'to see and be seen' becomes a negative trait. The tuhao, for instance - often referred to the as the Beverly Hillbillies of China - prefer conspicuous luxury rather than subtle displays, and they are mocked relentlessly in social media (Lu 2013).

Another example of how inconspicuousness is a new harbinger for luxury comes from hip hop artists via the visual blurring out of brands in hip hop music videos in an effort to 'keep it real':

Viewers [of the videos] have been observed playing a guessing game with peers as to 
which brand appeared on the screen, which reinforces brand notoriety, recall and hyperbrand sensitivity. Traditionally such blurring of logos would have been viewed as hampering promotional activities (Wilson, 2011 p. 8).

Cronin, McCarthy and Collins (2012) highlight how inconspicuous consumption and a sense of luxury may also be communicated by consumers through even the most mundane of objects, in order to maintain a position that is perceived as conveying grounded realism, legitimacy, and authenticity:

Mundane consumption emerges as a motor-force in allowing ... consumers to surreptitiously maintain distinction and to protect their within-group identity from mainstream co-optation. We ... suggest... that the inconspicuous nature of mundane consumables such as food and alcohol products allows for idiosyncratic shared community performances that are covert and difficult for broader social currents to detect and co-opt (p. 1).

That is, in order to ensure that other groups without the accumulated cultural capital of the hipsters being studied by Cronin et al. (2012) do not co-opt their tastes, inconspicuous consumables are preferred. This is an example of what Hebdige (1979) has suggested: selecting subtle signals can be a deliberate strategy to restrict imitation by making tastes hard to copy.

"These strategies work in tandem to ensure that hipsters idiosyncratically create their own distinction based on subtle opposition to the mainstream using the mundane or inconspicuous." (Cronin, et al., 2012, 10).

Wilson (2014) also points out that this desire for inimitability is a way of presenting a form of authenticity to the world. 
This use of inconspicuousness is in line with Brooks' (2001) suggestion that while consumers with high economic capital consume in ways others cannot imitate (e.g., purchasing yachts, eating caviar), the educated elites will consume rarefied versions of working class products (free range chicken, heirloom tomatoes - see also Potter 2010). In this way the educated elite - those high in cultural capital but not as high in economic capital - differentiate themselves from both the moneyed elite (and nouveaux riches) as well as the working class, and neither group will poach their signals (Brooks 2001). After all, if tastes can be copied, they will be abandoned in identity-relevant contexts (Berger and Heath 2007), so that people are not misidentified by signalling undesired identities (Berger and Heath 2008). There is even a price premium put on brand signals remaining a secret between those able to decipher them (Han, Nunes, and Dreze 2010). Sophistication and subtlety are significant components in inconspicuousness, as inconspicuousness represents a postmodern affectation and pull toward ostensive self-effacement. Perhaps this is in part out of a fear that overt conspicuousness may attract subsequent negative exposure; especially with the advent of social media, viral messaging, and trolling, where image control is eroded and sacrificed in favour of collective ownership.

A key focus here has been the elevation of the ritual significance of subtly ostentatious consumption as an in-group signal. We know that those within a group often share a common sense of self (Aron, Aron, and Smollan 1992; Belk 1988; Lastovicka and Fernandez 2005) and similarly that those who share rituals are likely to share a common aggregate extended sense of self (Gainer 1995). As these practices become more common, this also means that overt conspicuousness may be a declining phenomenon that becomes a stigmatized signifier of nouveaux riches, wannabes, and clueless conformists swept up in the tail end of the bandwagon 
effect (Lu 2013). Still, with citizen fashion bloggers, Google searches, and Web 2.0 connectivity, Simmel's (1904/2011) trickle-down theory may still set off a cycle of aspirational inconspicuousness that will instigate yet further innovations in subtlety by the cognoscenti.

\section{Theoretical Implications}

We demonstrate the rise of inconspicuously branded consumption, which is in dramatic contrast to the past hundred years or more of increasing conspicuousness in the marketplace, and we note the decoupling of the construct of luxury from conspicuousness, to which it has been tightly tied since Veblen (1899) and Simmel (1904). Additionally, in the past, someone could signal status to society at large and their social group peers simultaneously, but now, this is no longer the case; these two functions have also been decoupled. We point to a variety of factors that have led us to challenge conventional understandings of the role of conspicuousness in luxury and the use of conspicuousness as a signal: the signaling ability of traditional luxury goods being diluted, a preference for inconspicuousness given current economic conditions, and

an increased desire for sophistication and subtlety in design in order to further distinguish oneself for a narrow group of peers. Accordingly, the way that luxury is thought about and used is different in today's contemporary consumer culture and the way that consumption and brands are used to signal status or class affiliations has changed.

We need to rethink Veblen's conceptualization of conspicuousness, which in turn leads us to ask, what are the signalling qualities of brands in today's marketplace, and what is the purpose of luxury in today's global world? Or perhaps we need to read Veblen more carefully, for he also said,

The earlier and cruder method of advertisement held its ground so long as the public to which the exhibitor had to appeal comprised large portions of the community who were 
not trained to detect delicate variations in the evidences of wealth and leisure. The method of advertisement undergoes a refinement when a sufficiently large wealthy class has developed, who have the leisure for acquiring skill in interpreting the subtler signs of expenditure. "Loud" dress becomes offensive to people of taste, as evincing an undue desire to reach and impress the untrained sensibilities of the vulgar (p. 187).

Roper, Caruana, Medway, and Murphy (2013) argue that the construct of luxury needs to be rethought in contemporary markets due to the prominence of 'masstige' alongside a continued pressure to denote individuality. In response to this, we would argue that luxury no longer demarcates a particular social class or lifestyle (Hemetsberger, et al. 2012); rather, luxury is a socially constructed and largely subjective experience (Roper et al. 2013).

This new conceptualization of inconspicuousness allows us to better understand recent findings in the literature. For example, Nakassis (2012) points out that for lower social class consumers in India, the particular brand on an article of clothing doesn't matter, as they do not know individual Western brands anyway, but the fact that a garment has a brand on it - any brand - is quite important to these consumers. Thus, for these consumers the aesthetics of brandedness is conspicuous, but individual brands are inconspicuous, or irrelevant. This way of theorizing the meaning and importance of brands puts a further twist on how and why inconspicuous brands can be valued.

Additionally, Brown, McDonough and Schultz (2013) have recently suggested that ambiguous brands, which do not have clarity of meaning, but rather have identities that are imprecise, have longevity in terms of consumer appeal. Brand ambiguity allows consumers to attach varying salient meanings to the brand over time, allowing them to have an increased longevity compared to brands that have clear, well carved out, and rigid meanings. This departure from standard brand management theory can be understood in conjunction with the trend toward inconspicuous brands. As we have shown, brands that send subtle brand signals 
rather than overt ones are becoming more successful and appreciated by consumers. These signals are more easily misidentified by the general public, although not by insiders. Similar to the ambiguous brands discussed by Brown et al. (2013), consumers will better be able to attach their own meanings to inconspicuous brands, because the signals are not as clear, as with the lower middle class Indians studied by Nakassis (2012).

We argue that through analysing these economic and social trends that are leading to the rise of inconspicuousness, we can redefine the luxury construct by decoupling it from conspicuousness. We see this as an important shift that will have implications for our understanding of brand management, consumer behaviour, and consumer culture more broadly. From a brand management perspective, there are design implications; for example, Han, Nunes and Dreze (2010) find that inconspicuous brands are less likely to be counterfeited. From a consumer behaviour perspective, inconspicuous brands can help to defuse potential malicious envy (Belk 2011), for if the brand is not recognised by lower status viewers as being an expensive luxury, they can hardly feel envious at all. This is something that Bourdieu (1984, p. 283) also referred to in suggesting that higher social status groups prefer inconspicuous consumption in order to preserve social harmony (see also Wong 2007). Finally, from a consumer culture perspective, implications relate to questioning attempts to gain dignity within global consumer culture and whether and how rapidly "leaping luxuries" (Belk 1999) will continue to be common in emerging markets. That is, if the tendency to feel deprived of what everyone else seems to have fosters both a perceived loss of dignity and subsequent sacrifices of "necessities" in order to afford such "decencies," then the rise of inconspicuous consumption may act to mitigate such feelings of deprivation and their potentially harmful effects. 
In sum, the inconspicuousness that we describe may not be so much a decline in conspicuousness as a narrowing of the target audience for a brand to the cognoscenti. The appeal of being part of a group of insiders who know the secret has a long history, but is being reinvented in the context of inconspicuous consumption (Bok 1983). For example, Han, Nunes and Dreze (2010) suggest that only those at the highest socio economic level in society will appreciate inconspicuous brand signals. We suggest this phenomenon is much more widespread, and propose that is due to societal shifts such as a shift to non-material consumption and a preference for access rather than ownership (Bardhi and Eckhardt 2012; Belk forthcoming). It is difficult to call this post-materialism; status still matters both within narrow subtle brand communities and to those who embrace alternative status systems like hipsters. But as experiential consumption gains in importance, it may well become post-material (see Potter 2010; Yeoman, Munro, and McMahon-Beattie 2006).

\section{Managerial implications}

We mentioned in the opening vignette that the Ralph Lauren pony logo is getting larger in many parts of the world, while other high end fashion products are becoming more inconspicuous. Some brands, such as Louis Vuitton, seem to be moving wholesale toward becoming more inconspicuous, whereas other brands are both conspicuous and inconspicuous depending on the market and target segments they are trying to reach. For example, Mercedes is increasing the conspicuousness of their branding efforts in China, while at the same time introducing the new Denza brand which will radiate luxury and national pride in a much more inconspicuous way. Tom Ford's Private Blend collection of fragrances with their plain logo and typography, dark bottles, and muted packaging are designed to be inconspicuous. Yet in the Gulf region, where conspicuousness is important, the bottle size increases from the global standard of 
$50 \mathrm{ml}$ to $250 \mathrm{ml}$. Thus, while we see the shift toward inconspicuousness as an overarching, global trend, we do not necessarily see it as mutually exclusive from conspicuousness within a brand portfolio. Emirates Airlines uses space to control conspicuousness. In Dubai airport Emirates terminal, first class and business class lounges each have balconied floors to themselves. Passengers board the double decker Airbus A380s from each of these floors. It is no longer the case that the economy classes walk past the seats of those in first and business class. As such, the 'haves' afforded inconspicuousness. We are in a transition period, and we will see a mix of conspicuousness and inconspicuousness for the near future, which points toward the need for access to data and experts with real-time culturally specific insight, across several geographies, able to trend-spot.

We can see this ambiguity between conspicuousness and inconspicuousness in other ways as well. Tesla is criticized for being unrecognizable on the street unless you know what to look for (the logo does have a modified "T" shape). Perhaps this is intentional to make the brand visible only to the cognoscenti, adding some extra in-group exclusivity. Just as JP Morgan reputedly said "If you have to ask (the price) you can't afford it," perhaps the new mantra is "if you have to ask (the brand) you can't appreciate it." Presumably the new inconspicuous luxury consumer will not be criticized and rather will be celebrated for their restraint in the future.

\section{Future research}

While we have identified and theorized the phenomenon of inconspicuous branding, it will be important to conduct empirical research on the complexity of inconspicuousness in a variety of cultural and consumer contexts. What will the rise of inconspicuousness mean for the way that social relations and hierarchies play out using consumption signs and symbols in varying cultural, social and economic contexts? How are constructs such as luxury being 
redefined at the emic level and differentially utilized in an era of inconspicuousness? Will the nature of cultural capital in consumption change and if so how? These are just a few of the important future research questions that we hope will be addressed as this research stream moves forward. 


\section{References}

Allhoff, F., ed. (2008). Wine and Philosophy: A Symposium on Thinking and Drinking. Malden, MA: Blackwell.

Anaya, S. (2013). "Has logo fatigue reached a tipping point?" The Business of Fashion, 11 March, http://www.businessoffashion.com/2013/03/has-logo-fatigue-reached-a-tippingpoint.html.

Aron, A., E. Aron, and D. Smollan (1992). "Inclusion of Other in the Self Scale and the Structure of Interpersonal Closeness." Journal of Personality and Social Psychology, 64 (3), 596612.

Arvidsson, A. (2006). Brands: Meaning and Value in Media Culture. Abingdon: Routledge.

Bardhi, F. and G. Eckhardt (2012). "Access based consumption: The case of car sharing." Journal of Consumer Research, 39 (4), 881-898.

Bauer, M., S. von Wallpach and A. Hemetsberger (2011). "'My little luxury' - A Consumercentered, Experiential View." Marketing Journal of Research and Management, 38(1), 5766.

Bayley, S. (1991). Taste: The Secret Meaning of Things. New York: Basic Books.

Belk, R. (1985). "Materialism: Trait Aspects of Living in the Material World." Journal of Consumer Research, 12 (3) December, 265-280.

(1988). "Possessions and the Extended Self." Journal of Consumer Research, 15 (2), 139-68

(1999). "Leaping Luxuries and Transitional Consumers.” In Marketing Issues in Transitional Economies, Rajiv Batra, ed., Norwell, MA: Kluwer, 1999, 38-54. Partially reprinted in Transition, 10 (5), October, 24-6.

(2008). "Envy and Marketing." In Richard Smith, ed., Envy: Theory and Research. Oxford: Oxford University Press, 211-226.

(2011), “Benign Envy,” Academy of Marketing Science Review. 1 (December), 117-

34.

(forthcoming). "You are What You can Access: Sharing and Collaborative Consumption Online." Journal of Business Research.

Belk, R. and R. Pollay (1985). "Materialism and Status Appeals in Japanese and U.S. Print Advertising: An Historical and Cross-Cultural Content Analysis." International Marketing Review, 2 (December), 1985, 38-47.

Berger, J. and C. Heath (2008). "Who drives divergence? Identity signaling, outgroup dissimilarity and the abandonment of cultural taste." Journal of Personality and Social Psychology, 95(3), 593-607. 
Berger, J. and C. Heath (2007). "Where consumers diverge from others: Identity signaling and product domains." Journal of Consumer Research, 34(3), 121-134.

Berger, J. and M. Ward (2010), "Subtle Signals of Inconspicuous Consumption.” Journal of Consumer Research, 37 (4), 555-69.

Bergstrom, M. (2012). All Eyes East - Lessons from the Front Lines of Marketing to China's Youth. New York: Palgrave MacMillan.

Bloch, F., V. Rao, and S. Desai (2004). "Wedding Celebrations as Conspicuous Consumption." Journal of Human Resources, 39 (3), 675-95.

Bok, S. (1983). Secrets: On the Ethics of Concealment and Revelation. New York: Pantheon.

Bourdieu, P. (1984). Distinction: A Social Critique of the Judgment of Taste. London: Routledge and Kegan Paul.

Brooks, D. (2001). Bobos in Paradise: The new upper class and how they got there. New York: Simon and Schuster.

Brooks, J. (1981). Showing Off in America. Boston: Little Brown.

Brown, S. (2001). Marketing: The Retro Revolution. London: Sage.

Brown, S., P. McDonough and C. Schultz (2013). "Titanic: Consuming the Myths and Meanings of an Ambiguous Brand." Journal of Consumer Research, 40(4), 595-614.

Chadha, R. and P. Husband (2006). The Cult of the Luxury Brand: Inside Asia's Love Affair with Luxury. London: Nicholas Brealey.

Charles, K., E. Hurst, and N. Roussanov (2007). "Conspicuous Consumption and Race." Working Paper 13392, National Bureau of Economic Research, Cambridge, MA, September.

Chung, E. and E. Fischer (2001). "When Conspicuous Consumption Becomes Inconspicuous: The Case of Migrant Hong Kong Consumers." Journal of Consumer Marketing, 18 (6), 474-87.

Costa, J. and R. Belk (1990). "Nouveaux Riches as Quintessential Americans: Case Studies of Consumption in an Extended Family." Advances in Nonprofit Marketing, 3, Greenwich, CRT: JAI Press, 83-140.

CPP Luxury (2013). "Building a new customer base as tastes evolve - major challenges in China for luxury." CPP-Luxury.com, November 27. http://www.cpp-luxury.com/building-a-newcustomer-base-as-tastes-evolve-major-challenge-in-china-for-luxury/

Croll, E. (2006). China's New Consumers: Social Development and Domestic Demand. New York: Routledge. 
Cronin, J., M. McCarthy, and A. Collins (2012). "Covert Distinction: How Hipsters Practice Food-based Resistance Strategies in the Production of Identity." Consumption Markets and Culture, 15 (1), 1-27.

Danesi, M. (2006). Brands. New York: Taylor and Francis.

Danziger, P. (2005). Let Them Eat Cake: Marketing Luxury to the Masses - as Well as the Classes. Chicago: Dearborn Trade Publishing.

Dittmar, H. (1992). The Social Psychology of Material Possessions: To Have is to Be. Hemel Hempstead, UK: Harvester Wheatsheaf. (2008). Consumer Culture, Identity and Well-Being: The Search for the "Good Life" and the "Body Perfect." Hove, UK: Psychology Press.

Dougan, L. (2012). “Logo Mania.” H\&M Magazine, Winter, 26-7.

Douglas, M. and B. Isherwood (1979). The World of Goods: Towards an Anthropology of Consumption. New York: W. W. Norton.

Doyle, K. (1999). The Social Meanings of Money and Property: In Search of a Talisman. Thousand Oaks, CA: Sage.

Eastman, J., B. Fredenberger, D. Campbell, and S. Calvert (1997). “The Relationship Between Status Consumption and Materialism: A Cross-Cultural Comparison of Chinese, Mexican, and American Students." Journal of Marketing Theory and Practice, 5 (Winter), 54-66.

Eastman, J., R. Iyer, and S. Thomas (2013). "The Impact of Status Consumption on Shopping Styles: An Exploratory Look at the Millennial Generation.” Journal of Marketing Management, 23 (3), 57-73.

Festinger, L. (1954). "A Theory of Social Comparison Processes.” Human Relations, 7 (May), $117-40$.

Fournier, S. (1998). "Consumers and their Brands: Developing Relationship Theory in Consumer Research.” Journal of Consumer Research, 24 (March), 343-73.

Fussell, P. (1983). Class: A Guide Through the American Status System. New York: Summit Books.

Gainer, B. (1995), "Ritual and relationships: interpersonal influences on shared consumption." Journal of Business Research, 32 (3), 253-260.

Griffiths, M. (2013). Consumers and Individuals in China: Standing Out, Fitting In. London: Routledge.

Gronow, J. (1997). The Sociology of Taste. London; Routledge. 
Han, Y. J., J. Nunes and X. Dreze (2010). "Signalling Status with Luxury Goods: The Role of Brand Prominence." Journal of Marketing, 74(July), 15-30.

Hanser, A. (2008). Service Encounters: Class, Gender, and the Market for Social Distinction in Urban China. Stanford, CA: Stanford University Press.

Hebdige, D. (1979). Subculture: The meaning of style. London: Routledge.

Hemetsberger, A., S. von Wallpach and M. Bauer (2012). "'Because I'm worth it' - Luxury and the Construction of Consumers' Selves." in NA - Advances in Consumer Research Volume 40, eds. Zeynep Gürhan-Canli, Cele Otnes, and Rui (Juliet) Zhu. Duluth, MN : Association for Consumer Research, Pages: 483-489.

Hill, S., C. Rodeheffer, V. Griskevicius, K. Durante and A. White (2012). "Boosting Beauty in an Economic Decline: Mating, Spending, and the Lipstick Effect." Journal of Personality and Social Psychology, 103 (August), 275-291.

Hine, T. (1987). Populuxe: The Look and Life of America in the '50s and '60s, from Tailfins and TV Dinners to Barbie Dolls and the Fallout Shelter. New York: Alfred A. Knopf.

Holt, D. (1998). “Does Cultural Capital Structure American Consumption?” Journal of Consumer Research, 25 (June), 1-25.

(2004). How brands become icons: The principles of cultural branding. Cambridge: Harvard Business School Press.

Hudders, L. and M. Pandelaire (2013). "Indulging the Self Positive Consequences of Luxury Consumption." In Luxury Marketing: A Challenge for Theory and Practice, ed. KlausPeter Wiedman and Nadine Hennings, Wisebaden: Springer-Gabler, 119-38.

Lastovicka, J. and K. Fernandez (2005). "Three Paths to Disposition: The Movement of Meaningful Possessions to Strangers.” Journal of Consumer Research, 31 (4), 813-823.

Leach, W. (1993). Land of Desire: Merchants, Power, and the Rise of a New American Culture. New York: Random House.

Ledbury Research (2012). "Inconspicuous Consumption in the Bag." Financial Times, October, http://www.ledburyresearch.com/news/archive/inconspicuous-consumption-in-the-bag.

Leibenstein, H. (1950). "Bandwagon, Snob, and Veblen Effects in the Theory of Consumers' Demand." The Quarterly Journal of Economics, 64 (May), 183-207.

Levitt, S. and S. Dubner (2006). Freakonomics: A rogue economist explores the hidden side of everything. New York: Harper Collins.

Levy, S. (1986). "Meanings in Advertising Stimuli." in ed. Jerry Olson and Keith Sentis, Advertising and Consumer Psychology, Vol. 3, New York: Praeger, 214-226.

Lin, Y. (2011). Fake Stuff: China and the Rise of Counterfeit Goods. London: Routledge. 
Lu, P. X. (2008). Elite China: Luxury Consumer Behavior in China. Singapore: John Wiley \& Sons.

Lu, R. (2013). “Meet China's Beverly Hillbillies.” Foreign Policy, October 15. http://www.foreignpolicy.com/articles/2013/10/15/meet_chinas_beverly_hillbillies

Lury, C. (2004). Brands: The Logos of the Global Economy. London: Routledge.

Marchand, R. (1985). Advertising and the American Dream: Making Way for Modernity, 19201940. Berkeley, CA: University of California Press.

Mason, R. (1981). Conspicuous Consumption. New York: St. Martin's Press.

Mason, R. (1998). The Economics of Conspicuous Consumption: Theory and Thought Since 1700. Northampton: Edward Elgar.

Matt, S. (2003). Keeping Up with the Joneses: Envy in American Consumer Society, 1890-1930. Philadelphia: University of Pennsylvania Press.

McCracken, G. (1988). Culture and Consumption. Bloomington, IN: Indiana University Press. (2005). Culture and Consumption II. Bloomington, IN: Indiana University Press.

Mukherjee, R. (2007). "The Ghetto Fabulous Aesthetic in Contemporary Black Culture." Cultural Studies, 20 (6), 599-629.

Nakassis, Constantine (2012). "Counterfeiting What? Aesthetics of Brandedness and BRAND in Tamil Nadu, India." Anthropological Quarterly, 85 (3), 701-22.

Nueno, J. L. and J. A. Quelch, (1998). “The Mass Marketing of Luxury.” Business Horizons, 8 (November-December), 122-38.

Outka, E. (2009). Consuming Tradition: Modernity, Modernism, and the Commodified Authentic. Oxford: Oxford University Press.

Packard, V. (1959). The status seeker: An exploration of class behavior in America and the hidden barriers that affect you, your community, your future. New York: David McKay.

Pakulski, J. and M. Waters (1996). The Death of Class. London: Sage.

Pinheiro-Machado, R. (2010). "The Attribution of Authenticity to 'Real' and 'Fake' Branded Commodities in Brazil and China." In Cultures of Commodity Branding, ed. Andrew Bevan and David Wengrow, Walnut Creek, CA: Left Coast Press, 109-30.

Podolny, J. (2005). Status Signals: a Sociological Study of Market Competition. Princeton, NJ: Princeton University Press.

Polyani, C. (2001). The Great Transformation: The Political and Economic Origins of Our Time. Boston: Beacon Press. 
Postrel, V. (2008). "Inconspicuous Consumption: A New Theory of the Leisure Class." The Atlantic, http://www.theatlantic.com/magazine/archive/2008/07/inconspicuousconsumption/306845/.

Potter, A. (2010). The Authenticity Hoax: How We Get Lost Finding Ourselves. Toronto: McClelland and Stewart.

Roper, S., R. Caruana, D. Medway and P. Murphy (2013). "Constructing Luxury Brands: Exploring the Role of Consumer Discourse.” European Journal of Marketing, 47 (3/4), $375-400$.

Rucker, D. and A. Galinsky (2008). "Desire to Acquire: Powerlessness and Compensatory Consumption.” Journal of Consumer Research, 35 (2), 257-67.

(2013). "Compensatory Consumption." in The Routledge Companion to Identity and Consumption, ed. Ayalla Ruvio and Russell Belk, London: Routledge, 207-215.

Schimmel, S. (2008). "Envy in Jewish Thought and Literature.” in Envy: Theory and Research, ed. Richard H. Smith, Oxford: Oxford University Press, 17-38.

Schroeder, J. and M. Salzer-Mörling, ed. (2006). Brand Culture. London: Routledge.

Silverstein, M. and N. Fiske (2003a). "Luxury for the Masses.” Harvard Business Review, 81 (4), 48-57.

(2003b). Trading Up: Why Consumers Want New Luxury Goods-And How Companies Create Them. New York: Portfolio.

Simmel, G. (1904/2011). The Philosophy of Money. London: Routledge.

Sirgy, J., J. S. Johar, and M. Wood (1986). "Determinants of Product Value Expressiveness: Another Look at Conspicuousness, Differentiation, and Common Usage." Developments in Marketing Science, 9, Atlanta, GA: Academy of Marketing Science, 35-9.

Smith, B., ed. (2007). Questions of Taste: The Philosophy of Wine. Oxford: Oxford University Press.

Stearns, P. (1999). The Battleground of Desire: The Struggle for Self Control in Modern America. New York: New York University Press.

Stylus (2014). “Inconspicuous Consumption.” [Report] $6^{\text {th }}$ February 2014, London, pp.1-13, http://www.stylus.com/inconspicuousconsumption [Accessed 11th Feb 2014].

Sullivan, O. and J. Gershuny (2004). "Inconspicuous Consumption: Work-rich, time-poor in the Liberal Market Economy.” Journal of Consumer Culture, 4 (1), 79-100. 
Sundie, J., D. Kenrick, V. Grikevicious, J. Tybur, K. Vohs, and D. Beal (2011). "Peacocks, Porsches, and Thorstein Veblen: Conspicuous Consumption as a Sexual Signalling System.” Journal of Personality and Social Psychology, 100 (4), 664-80.

Tawney, R. H. (1920). The Acquisitive Society. New York: Harcourt Brace and Howe.

Taylor, J., D. Harrison, and S. Kraus (2009). The New Elite: Inside the Minds of the Truly Wealthy. New York: American Management Association.

The Economist (2005). "Inconspicuous Consumption: Now that Luxury has Gone Mass Market, How are the Super-rich to Flaunt their Wealth?" The Economist, http://www.economist.com/node/5323772/print.

The Economist (2013). "Beyond Bling: Luxury Goods in China," The Economist, June 8. http://www.economist.com/news/business/21579015-life-getting-harder-purveyors-luxurychina-growth-prospects-are-still.

Thomas, D. (2007). Deluxe: How Luxury Lost its Luster. New York: Columbia University Press.

Tian, K. and L. Dong (2011). Consumer-Citizens of China: The Role of Foreign Brands in the Imagined Future China. London: Routledge.

Truong, Y., G. Simmons, R. McColl and P. Kitchen (2008). "Status and conspicuousness - Are they related? Strategic Marketing Implications for Luxury Brands.” Journal of Strategic Marketing, 16(3), 189-203.

Twitchell, J. (2004). Branded Nation: The Marketing of Megachurch, College Inc., and Museumworld. New York: Simon and Schuster.

Veblen, T. (1899/1973). The Theory of the Leisure Class. Boston, MA: Houghton Mifflin.

Wang, J. (2010). Brand New China: Advertising, Media, and Commercial Culture. Cambridge, MA: Harvard University Press.

Warde, A. (1997). Consumption, Food, and Taste. London: Sage.

Watson, J., ed. (2006). Golden Arches East: McDonald's in East Asia, $2^{\text {nd }}$ ed. Stanford, CA: Stanford University Press.

Weisz, J., F. Rothbaum, and T. Blackburn (1984). "Standing Out and Standing In: The Psychology of Control in America and Japan.” American Psychologist 39, 955-969.

Wicklund, R. and P. Gollwitzer (1982). Symbolic Self-Completion. Hillsdale, NJ: Erlbaum.

Williams, A. and G. Atwal (2013). "The Hedonistic Consumption of Luxury and Iconic Wines." In Luxury Marketing: A Challenge for Theory and Practice, ed. Klaus-Peter Wiedman and Nadine Hennings, Wisebaden: Springer-Gabler, 379-94. 
Wilson, J.A.J. (2011). "New-School Brand Creation and Creativity - Lessons from Hip-Hop and the Global Branded Generation.” Journal of Brand Management, 19 (2), 91-111.

Wilson, J.A.J. (2014). "Inconspicuous Branded Consumption Is the New Business Buzzword in Retail.” Huffington Post, $6^{\text {th }}$ February, http://www.huffingtonpost.co.uk/jonathan-ajwilson/inconspicuous-branded-con_b_4734255.html [Accessed 11th Feb 2014].

Wilson, J.A.J. and J.E. Morgan (2011). "Friends or Freeloaders? Encouraging Brand Conscience and Introducing the Concept of Emotion-based Consumer Loss Mitigation." Journal of Brand Management, 18 (August), 659-76.

Wong, L. (2007). "Market Cultures, the Middle Classes and Islam: Consuming the Market?" Consumption Markets and Culture, 10 (4), 451-470.

Wong, N. and A. Ahuvia (1998). "Personal Taste and Family Face: Luxury Consumption in Confucian and Western Societies.” Psychology and Marketing, 15 (5), 423-441.

Wu, Z., J. Borgerson and J. Schroeder (2013). From Chinese brand culture to global brands: Insights from aesthetics, fashion and history. New York: Palgrave Macmillan.

Yeoman, I., C. Munro, and U. McMahon-Beattie (2006). "Tomorrows: World, Consumer and Tourist." Journal of Vacation Marketing, 12 (2), 174-190.

Zhou, N. and R. Belk (2004). "Chinese Consumer Readings of Global and Local Advertising Appeals." Journal of Advertising, 33 (Fall), 63-76. 